Article

\title{
Exploring Tradeoffs in Demand-Side and Supply-Side Management of Urban Water Resources Using Agent-Based Modeling and Evolutionary Computation
}

\section{Lufthansa Kanta ${ }^{1}$ and Emily Zechman Berglund ${ }^{2, *}$}

1 Zachry Department of Civil Engineering, Texas A\&M University, 3136 TAMU, College Station, TX 77843-3136, USA; E-Mail: kanta.lufthansa@ gmail.com

2 Civil, Construction, and Environmental Engineering, North Carolina State University, Campus Box 7908, Raleigh, NC 27695-7908, USA

* Author to whom correspondence should be addressed; E-Mail: emily_berglund@ncsu.edu; Tel.: +1-919-515-2338; Fax: +1-919-515-7908.

Academic Editors: Koen H. van Dam and Rémy Courdier

Received: 2 August 2015 / Accepted: 10 November 2015 / Published: 13 November 2015

\begin{abstract}
Urban water supply systems may be managed through supply-side and demand-side strategies, which focus on water source expansion and demand reductions, respectively. Supply-side strategies bear infrastructure and energy costs, while demand-side strategies bear costs of implementation and inconvenience to consumers. To evaluate the performance of demand-side strategies, the participation and water use adaptations of consumers should be simulated. In this study, a Complex Adaptive Systems (CAS) framework is developed to simulate consumer agents that change their consumption to affect the withdrawal from the water supply system, which, in turn influences operational policies and long-term resource planning. Agent-based models are encoded to represent consumers and a policy maker agent and are coupled with water resources system simulation models. The CAS framework is coupled with an evolutionary computation-based multi-objective methodology to explore tradeoffs in cost, inconvenience to consumers, and environmental impacts for both supply-side and demand-side strategies. Decisions are identified to specify storage levels in a reservoir that trigger: (1) increases in the volume of water pumped through inter-basin transfers from an external reservoir; and (2) drought stages, which restrict the volume of water that is allowed for residential outdoor uses. The proposed methodology is demonstrated for Arlington, Texas, water supply system to identify non-dominated strategies for an historic drought decade. Results demonstrate that pumping costs associated with maximizing
\end{abstract}


environmental reliability exceed pumping costs associated with minimizing restrictions on consumer water use.

Keywords: agent-based modeling; complex adaptive systems analysis; multi-objective optimization; urban water resources management; sustainability

\section{Introduction}

Urban water management can specify supply-side infrastructure and demand-side policies to balance water resources for municipal and environmental needs. Early water management initiatives focused on supply-side management through the expansion of water infrastructure systems and acquisition of new sources to meet domestic, agricultural, and industrial needs [1,2]. Due to population growth, urbanization, and climate change, water supplies have become increasingly stressed, and water utilities have turned to demand-side management through implementation of water conservation activities, including promoting water use efficiency, encouraging indoor and outdoor conservation, setting water prices, recycling and reusing water, and identifying leaks $[3,4]$. Supply-side management options may result in significant environmental degradation by diverting water from ecosystem requirements, and large infrastructure projects may bear enormous costs. By reducing demands for freshwater, demand-side strategies may better protect environmental systems, but the cost and performance of demand management strategies are uncertain. Incentives to use less water through pricing may have limited application and require institutional frameworks to implement. Water use standards, such as new appliances and water restrictions, may increase awareness of water issues and result in more water savings; however, they have typically been cost-ineffective in implementation [5]. Demand management may have unintended social effects and create an imbalance in environmental justice, as consumers in diverse socioeconomic groups may experience water shortages and price increases differently [6]. Other social effects may emerge due to excessive water use restrictions that affect property values or frustrate residents [7]. Water use reductions may be highly unpredictable; low response rates may not conserve adequate water supplies, while high response rates may reduce water utility revenue [8].

Many water management studies developed tools and frameworks to evaluate the performance of supply-side management options. The performance of demand-side strategies, however, is the outcome of the decisions and behaviors of consumers and is not easily simulated through readily available engineering models. To capture the feedbacks among water resources, consumers, and decision-makers, a modeling approach is developed and applied here to represent the comprehensive water resources system as a Complex Adaptive System (CAS). A CAS is a system of agents that update decentralized decisions based on dynamic feedback from a shared environment and the decisions of other agents. A CAS framework is developed by using agent-based models (ABM) to represent a policy maker that manages water resources and residential households that consume water and select water conservation practices. The policy maker agent subsidizes appliance replacements, implements year-round water restriction ordinances, and allocates inter-basin transfers. Residential agents respond to messages from the policy maker agent and communicate about water use and conservation. The shared water resources environment is characterized as a system of reservoirs, surface water systems, and watershed processes. 
The CAS modeling framework was developed to simulate urban water resources $[9,10]$ and is extended in this research to explore the sustainability of using demand-side and supply-side management for water resources through a multi-objective approach. The CAS framework is coupled with an evolutionary computation-based multi-objective optimization methodology, the non-dominated sorting genetic algorithm II (NSGA-II) [11]. An optimization model is developed to identify optimal inter-basin transfer pumping schedules and water restriction policies for a large-scale water resources system. Supply-side and demand-side management policies are evaluated based on the tradeoffs among cost to the utility, inconvenience to consumers, and environmental impacts. The proposed methodology is applied and demonstrated for the water supply system for the city of Arlington (TX, USA).

\section{Problem Description}

Managing urban water resources is inherently a multi-criteria problem, as utilities must balance the needs of residential, industrial/commercial, and environmental water users. Over the last several decades, various optimization models have been developed in assessing and managing urban water resources. A number of studies focused on supply-side management decisions through initiating inter-basin transfers, expanding reservoir capacity, and installing desalination plants to minimize operation and maintenance costs [12-17]. The majority of these studies confirm a tradeoff between management cost and water supply reliability. In an effort to evaluate demand reduction through water conservation activities, several studies simulated demand-side management decisions, such as plumbing fixture replacements, outdoor watering restrictions, and water rationing to minimize management costs [18-22]. While these studies acknowledged that the interaction between supply-side and demand-side options affects optimal management decisions, the simulation-optimization approaches focused on supply-side or demand-side decisions in isolation. Further, these studies neglected feedbacks among consumers, policy makers, and natural resources that can alter the performance of management strategies.

In exploring and simulating demand-side strategies, scholars and water managers have developed a range of techniques to estimate of demand projections, which is typically accomplished through the use of time series and econometric models [23]. Total demand may be influenced by changes in water pricing, conservation policies, and climate change, which drive consumer behaviors, such as the adoption of water-consuming appliances; lawn and gardening practices; and conservation. Thus demand is a dynamic process, which emerges due to interactions among consumers, policy makers, and the water use environment. This type of dynamic and adaptive system can be simulated using an ABM approach where agents represent individual reactive and autonomous decision-making units, including human actors, and are capable of adapting to inputs from other agents and a shared environment through a set of logical and mathematical rules that specify behavioral decisions [24-26]. Several studies of urban water management used ABM approaches and focused primarily on demand-side management through pricing [27,28] and non-pricing [2,29-31] conservation measures; none of these studies, however, incorporated supply-side decisions. Giacomoni et al. [9] developed an ABM framework to simulate the dynamics of land use change, population growth, and adaptations of water demands and the effects on water sustainability. The framework was applied to simulate alternative demand-side management strategies, including outdoor watering restrictions, a rainwater harvesting rebate program, and a high-density land-use change policy [32]. Kanta and Zechman [10] extended this framework to explore both 
supply-side management and demand-side management through inter-basin transfers and water conservation options to explore scenario-based adaptive water management strategies. This investigation showed that supply-side policy decisions, such as pumping water from an external basin, are not independent of demand-side management options, such as indoor-outdoor water use restrictions. Thus, further investigation is needed to evaluate optimal supply-side and demand-side water management strategies, including inter-basin transfers, drought management plans, and indoor incentive-based strategies to minimize management costs.

\section{Overview of CAS Framework}

A CAS framework was developed to simulate non-linear feedbacks among consumers, policy makers, and the water resources system [10]. The framework consists of three major components: an ABM of residential consumers, an ABM of a policy maker, and a mechanistic water resources model. Consumer demands vary based on seasonal needs for watering lawns, adoption of water conservation technologies, and compliance with water use restrictions. A policy maker agent implements drought management plans, which include outdoor water use restrictions based on the current reservoir storage, and fixture incentive programs, such as replacing appliances with low-flow toilets, low-flow showers, and efficient washing machines. Historic climatic data that include the drought-of-record are simulated to explore the dynamic interactions among conservation, drought management, and inter-basin transfers and to evaluate adaptive water management strategies. The CAS framework is developed using AnyLogic 6.5 simulation software [33]. A detailed description can be found in Kanta and Zechman [10]; however, a brief description of the model is provided here.

\subsection{Agent-Based Model of Residential Consumers}

Each household in a water district is represented as an agent who demonstrates heterogeneous and adaptive water use behavior. Agent's heterogeneity is introduced through month specific demand, year of house built, and lot size. The monthly demand for each household is estimated based on the water district's billing data which contains customer specific water usage volume per month for a long time horizon. From the statistical analysis of the water consumption data, a gamma distribution is chosen as a best fit to model the water use of agents [10] which stochastically satisfies the following relation:

$$
E_{m}(\text { Demand })=E_{m}\left\{\text { Usage } \mid P_{r}(X \leq x)\right\}
$$

where $E_{m}($ Demand $)=$ expected demand for month $m\left(\mathrm{~m}^{3} /\right.$ month $) ; E_{m}\{$ Usage $\mid \operatorname{Pr}(X \leq x)\}=$ expected value of water usage for month $m$ from gamma fitted distribution with a given probability of non-exceedance ( $\mathrm{m}^{3} /$ month); $X=$ a uniform random variable $[0,1]$; and $x=$ a possible value of $X$. The gamma fitted stochastic model ensures agent's heterogeneity in terms of water use at the beginning of the simulation period which may change if an agent adopts a water efficient technology or complies with any water use restrictions imposed by the water district.

Each agent is also associated with three indoor end-uses, including toilet, shower head, and washing machine, and one outdoor end-use, the sprinkler system. The build year of the house determines if the existing appliances are old (water-inefficient) or new (relatively water-efficient). The lot size determines 
the possible size of gardens and lawns for each household. Both the indoor end-uses and outdoor sprinkler demand are modeled after Jacobs and Haarhoff [34]:

$$
\begin{gathered}
A M D D_{i, e, m}=a_{e, m} \times b_{e} \times n \\
A M D D_{o, m}=\left(f_{m} \times s\right) \frac{\left(k_{m} \times E V_{m}\right)-P_{m}}{d_{m}} \\
P_{m}=\left\{\begin{array}{c}
R_{m} ; \text { for } R_{m}<25 \mathrm{~mm} \\
0.504 R_{m}+12.4 ; \text { for } 25 \mathrm{~mm} \leq R_{m}<152 \mathrm{~mm} \\
89.0 ; \text { for } R_{m} \geq 152 \mathrm{~mm}
\end{array}\right\}
\end{gathered}
$$

where $A M D D_{i, e, m}=$ average monthly daily demand for indoor appliance $e$ during month $m$ (L/day); $a_{e, m}=$ volume parameter of indoor appliance $e$ during month $m$ (L/event); $b_{e}=$ frequency parameter of indoor appliance $e$ (number of events/person/day); $n=$ household size; $A M D D_{o, m}=$ average monthly daily outdoor demand during month $m$ (L/day); $f_{m}=$ a model parameter representing a household's behavioral choice of over- or under-watering the lawn with respect to the ideal water requirement (unitless); $s=$ surface area of garden and lawn $\left(m^{2}\right)$, which is a function of lot size; $k_{m}=$ crop factor during month $m$ (unitless); $E V_{m}=$ pan evaporation during month $m(\mathrm{~mm} / \mathrm{month}) ; P_{m}=$ the portion of rainfall that penetrates into the soil during month $m(\mathrm{~mm} / \mathrm{month}) ; d_{m}=$ number of days in month $m$ (days/month); and $R_{m}=$ rainfall during month $m$ (mm/month). The factor $k_{m} \times E V_{m}$ represents evapotranspiration from the lawn or garden. The volume parameter $\left(a_{e, m}\right)$, frequency parameter $\left(b_{e}\right)$, and household's behavioral choice $\left(f_{m}\right)$ values are adopted from Jacobs and Haarhoff [34].

A social communication model, or word-of-mouth framework [10], is developed based on Watts-Strogatz model [35] to simulate agents' communication about technology adoption. The parameters of this model are cluster size, degree of connection, and the technology adoption threshold. Each agent is initialized randomly as a member of a cluster at the beginning of simulation period. Each Agent also has a user defined number of connections. When a policy maker agent offers incentive based programs, such as toilet/shower head/washing machine replacement rebate, the consumer agents adopts the new water efficient appliances and send information about technology adoption to their corresponding social network through the connections. The initial adoption of technology is determined randomly, without incorporation of a consumer price model. A threshold based decision rule is used to model voluntary adoption of water efficient technology, regardless of incentives offered by the policy maker agent. An agent adopts voluntarily once a certain portion of its social network has adopted. A detailed sensitivity analysis of word-of-mouth framework was done by Kanta and Zechman [10], which concludes that the model is more sensitive to cluster size and threshold value; the number of connections, on the other hand, does not have any significant effect on the rate of voluntary adoption.

All consumers begin with old or new appliances based on the age of their corresponding houses. Each year, the policy maker agent offers a rebate to a specified number of randomly selected agents, which accept the rebate and replace existing appliances with water-efficient appliances. The reduction in demand for each appliance is modeled using end-use model (Equation (2)) with a reduced value of the volume parameter, $a_{e, m}$. Agents who reduce demands through adopting water efficient technologies, send information to their peers. Based on the information received from a social network, consumers may voluntarily adopt water efficient appliances, an aggregation of which may also result in demand reduction. 
The outdoor demand is a function of climatic data ( $E V_{m}$ and $R_{m}$ in Equations (3) and (4), respectively), size of lawns and gardens ( $s$ in Equation (3)), and affinity of a household to over- or under-water in maintaining gardens and lawns $\left(f_{m}\right.$ in Equation (3)). Agents reduce outdoor demands based on outdoor watering restrictions. All agents are initialized with $f_{m}=2.0$ in Equation (3), which represents a frequency of outdoor watering at five times per week. It is assumed that all outdoor watering restrictions are mandatory. When a restriction is implemented, the outdoor demand is reduced based on the watering restrictions as twice per week (corresponding to drought stage 1 and $f_{m}=1.0$ ), once per week (drought stage 2 and $f_{m}=0.5$ ), and banned completely (drought stage 3 and $f_{m}=0.0$ ). The total demand for each agent is calculated as a sum of indoor and outdoor demand with reduction at the above four end-uses.

\subsection{Agent-Based Model of Policy Makers}

The utility manager is modeled as a policy maker agent that offers incentive-based conservation programs, imposes water use restrictions, and allocates inter-basin transfers. Both the incentive-based appliance replacement program and outdoor watering restriction options are adopted from the water district's current conservation plan, and data is not included describing the water district's price data and consumer specific income data. At the beginning of each month, the policy agent evaluates the level of the reservoir compared to the conservation pool, selects inter-basin transfer volumes, and imposes conservation and restrictions accordingly. The conservation pool of a reservoir represents the water surface elevation whose equivalent storage is allocated for the purposes of water supply, irrigation, recreation, and hydropower generation. The policy maker agent implements drought stages based on the volume of water stored in a reservoir at each month. The policy maker agent also determines the volume of water supplied through inter-basin transfers based on the reservoir storage. For months when the total demand is greater than the supply, and the demand cannot be met, the policy agent restricts outdoor water use completely. Each year, the policy agent implements monthly toilet, shower, and washing machine replacement rebate programs for the residential consumers.

\subsection{Water Resources Model}

The water resources model simulates the hydrologic processes of a watershed and the reservoir. Runoff from the watershed is calculated using the Rational Method [36] to generate inflow to the reservoir. The reservoir receives additional inflows from inter-basin transfers, and outflows include customer withdraws, evaporation, and reservoir spills. Due to changes in both inflows and outflows throughout the year, the reservoir storage and surface level vary with time. The water balance equation is used to calculate reservoir storage as follows:

$$
S_{t}=S_{t-1}+R O_{t}+I B T_{t}-D_{t}-L E_{t}-R_{t}
$$

where $S_{t}=$ reservoir storage volume at current month $t\left(\mathrm{~m}^{3}\right) ; S_{t-1}=$ reservoir storage volume at the previous month $t-1\left(\mathrm{~m}^{3}\right) ; R O_{t}=$ runoff from the watershed into the reservoir at current month $t\left(\mathrm{~m}^{3}\right)$; $I B T_{t}=$ inter-basin transfer volume to the reservoir at current month $t\left(\mathrm{~m}^{3}\right) ; D_{t}=$ residential demand at current month $t\left(\mathrm{~m}^{3}\right) ; L E_{t}=$ lake evaporation at current month $t\left(\mathrm{~m}^{3}\right)$; and $R_{t}=$ reservoir release at current month $t\left(\mathrm{~m}^{3}\right)$. Reservoir releases are set at the required instream flow volume if storage volume does not exceed reservoir capacity. The instream flow for environmental/ecological purposes can be estimated as 
$10 \%$ to $15 \%$ of average annual runoff from the watershed, as suggested by Cai and Rosegrant [37]. When storage volume exceeds reservoir capacity, reservoir releases are calculated as the excess volume of water beyond the reservoir capacity.

\section{Optimization Model for Urban Water Resources Management}

\subsection{Model Formulation}

The water resources problem posed here explores tradeoffs among three objectives, including the minimization of pumping cost (Equation (6)), minimization of water use restrictions (Equation (7)), and maximization of provision of water for environmental flows (Equation (8)). The multi-objective optimization model is formulated as:

$$
\begin{gathered}
\text { Minimize } C=\sum_{t=0}^{m} \text { Cost_IBT }_{t} \\
\text { Minimize } O W R=\sum_{t=0}^{m} N_{S_{1}}+\sum_{t=0}^{m} N_{S_{2}}+\sum_{t=0}^{m} N_{S_{3}} \\
\text { Maximize } E R=\frac{\sum_{t=0}^{m} R_{t}}{\sum_{t=0}^{m} I F R_{t}}
\end{gathered}
$$

Subject to:

$$
\begin{gathered}
\sum_{t=0}^{m} S H_{t} \leq 0.0 \\
R_{t} \geq I F R_{t}
\end{gathered}
$$

where Cost_IBT $T_{t}=$ pumping cost for month $t$ for inter-basin transfers $(\$) ; t=$ simulation period or month; $m=$ total number of months in the simulation period; $O W R=$ outdoor watering restrictions (days); $N_{S_{1}}=$ number of days when stage-1 outdoor water use is restricted (days); $N_{S_{2}}=$ number of days when stage-2 outdoor water use is restricted (days); $N_{S_{3}}=$ number of days when stage-3 outdoor water use is restricted (days); $E R=$ environmental reliability for the water resources system (unitless); $R_{t}=$ reservoir release at month $t\left(\mathrm{~m}^{3}\right) ; I F R_{t}=$ instream flow requirement at month $t\left(\mathrm{~m}^{3}\right)$; and $S H_{t}=$ shortage volume during month $t\left(\mathrm{~m}^{3}\right)$. Equation (7) represents a quantitative measure of restrictions is the total number of days when outdoor watering restrictions are imposed. A stage-1 outdoor water use restriction specifies that lawn watering should be reduced to twice per week; a stage-2 outdoor water use restriction specified that lawn watering should be reduced to once per week; and a stage-3 restriction bans lawn watering altogether. Equation (9) ensures that consumer demand will be met during the simulation period. The constraint represented by Equation (10) ensures that the instream flow requirement is maintained year round, even during severe drought. 


\subsection{Model Decision Variables}

Eight decision variables are identified for the optimization problem, which are grouped into two categories: supply-side decision variables and demand-side decision variables. The supply-side decision variables include: (1) pumping triggers to initiate inter-basin transfers (represented as the percentage of reservoir conservation storage) and (2) volume of inter-basin transfers at each month $\left(\mathrm{m}^{3} / \mathrm{month}\right)$. The demand-side decision variables are drought triggers (represented as a percentage of reservoir conservation storage). Table 1 shows the list of decision variables. Note that although both the pumping triggers and the drought triggers are a function of reservoir conservation storage, the two triggers are simulated independently.

Table 1. List of model decision variables.

\begin{tabular}{cccc}
\hline Decision Variable & Description & Range & Decision Variable Type \\
\hline $\mathrm{X}$ & Level 1 pumping trigger & $0-1$ & Supply side \\
$\mathrm{Y}$ & Level 2 pumping trigger & $0-1$ & Supply side \\
$\mathrm{P}_{1}$ & Level 1 IBT volume & $0-12.3$ billion $\cdot \mathrm{m}^{3}$ & Supply side \\
$\mathrm{P}_{2}$ & Level 2 IBT volume & $0-12.3$ billion $\cdot \mathrm{m}^{3}$ & Supply side \\
$\mathrm{P}_{3}$ & Level 3 IBT volume & $0-12.3$ billion $\cdot \mathrm{m}^{3}$ & Supply side \\
$\mathrm{S}_{1}$ & Stage 1 drought trigger & $0-1$ & Demand side \\
$\mathrm{S}_{2}$ & Stage 2 drought trigger & $0-1$ & Demand side \\
$\mathrm{S}_{3}$ & Stage 3 drought trigger & $0-1$ & Demand side \\
\hline
\end{tabular}

\subsection{Non-Dominated Sorting Genetic Algorithm-II}

A simulation-optimization framework is developed by coupling the CAS framework with an evolutionary computation-based multi-objective methodology, NSGA-II, within AnyLogic 6.5 simulation software. NSGA-II is a genetic algorithm (GA) [38] based multi-objective approach. NSGA-II provides a population-based approach to search for a set of Pareto-optimal or non-dominated solutions. Each solution (or individual) in a population consists of a set of genes that represent the decision variables. The performance of each individual is evaluated using the CAS model, which initializes consumer agents, implements conservation and restriction policies imposed by a policy maker agent, simulates social communication between consumer agents, and calculates demands, reservoir storage, and objective function values. NSGA-II uses non-dominated sorting and a crowding distance operator in addition to typical GA operators of crossover, mutation, and selection. The operators are designed to ensure that the population will converge close to the true Pareto front and that solutions will be spread uniformly across the front.

The steps of the simulation-optimization procedure are as follows:

1. Generate an initial population of decision vectors of size $N$.

2. Apply section, crossover, and mutation operators to create a new population of size $N$.

3. Combine the parent and children population to generate a population of size $2 N$.

4. Execute CAS model to evaluate each decision vector and assign a value for each objective function.

5. Sort the population (decision vectors) into non-dominated fronts based on objective function vectors. 
6. For each front, calculate the crowding distance.

7. Select $N$ solutions based on crowding distance.

8. Repeat steps 2 to 7 until stopping criterion is satisfied.

\section{Case Study: Arlington Water System}

Arlington, located in North Central Texas, is selected to demonstrate the selection of demand-side and supply-side management strategies for urban water resources. The city of Arlington serves a population of over 3.6 million and is projected to grow to over 5 million by the year 2060 [39]. Arlington purchases raw water from Tarrant Regional Water District (TRWD) for storage in Lake Arlington. This study explores the selection of appropriate pumping triggers and drought stage triggers for Lake Arlington. Selection of high pumping triggers may result in a greater chance of reservoir spillage; on the other hand, selection of low pumping triggers may increase the severity of droughts. Similarly, lowering drought stage triggers for stage- 1 during the period of water shortage may increase the chance of experiencing stage-3 restriction over a prolonged period.

TRWD pumps water to Arlington from two reservoirs, Cedar Creek (firm yield = 216 million $\mathrm{m}^{3} / \mathrm{year}$ ) and Richland-Chambers (firm yield $=259$ million $\cdot \mathrm{m}^{3} / \mathrm{year}$ ) during low demand periods and stores the water in Lake Arlington (maximum capacity $=56.4$ million $\cdot \mathrm{m}^{3}$ with conservation storage capacity $=47.8$ million $\cdot \mathrm{m}^{3}$ ) for use during high demand periods. Lake Arlington supplies water to City of Arlington's Pierce Burch Water Treatment Plant (PB WTP) and two major external customers. PB WTP serves approximately $55 \%$ of Arlington population with a current demand of $46.7 \mathrm{million} \cdot \mathrm{m}^{3} / \mathrm{year}$. Currently, the City of Arlington offers a plumbing fixture replacement rebate program and implements three drought stages (stage-1, water watch; stage-2, water warning; and stage-3, emergency water use) based on Lake Arlington capacities. Cedar Creek and Richland-Chambers Reservoirs are modeled as infinite reservoirs (due to high storage capacity volumes), without limitations on supply capacity. Residential agents are initialized to represent 50,600 households, which are served by the Lake Arlington. At the end of each year, new agents are created based on a population growth rate of $2.6 \%$, which is a representative value for this area, based on historic data and population projections [40]. Each agent is also initialized as a member of a cluster of size 100 with eight social connections and threshold value of $50 \%$. A realistic conservation program, consisting of 2000 toilets, 2000 shower heads, and 2000 washing machines replacement rebate per year, imposed by the policy agent is applied throughout the simulation period. It is assumed that each household that responds to the appliance rebate program or communication via word-of-mouth replaces toilets, shower heads, and washing machine simultaneously. A schematic diagram of the Arlington water system is shown in Figure 1.

\subsection{Pumping Costs}

Monthly pumping data including pumping volume from Tarrant reservoirs to Lake Arlington and unit cost of pumping from the year 2000 to 2010 were collected from TRWD. Due to seasonal variation of energy cost, the pumping data were first grouped by months (January to December). A linear regression model was then applied to estimate cost of pumping for each month based on pumping volume. Table 2 lists the regression model coefficients in calculating monthly pumping costs. 


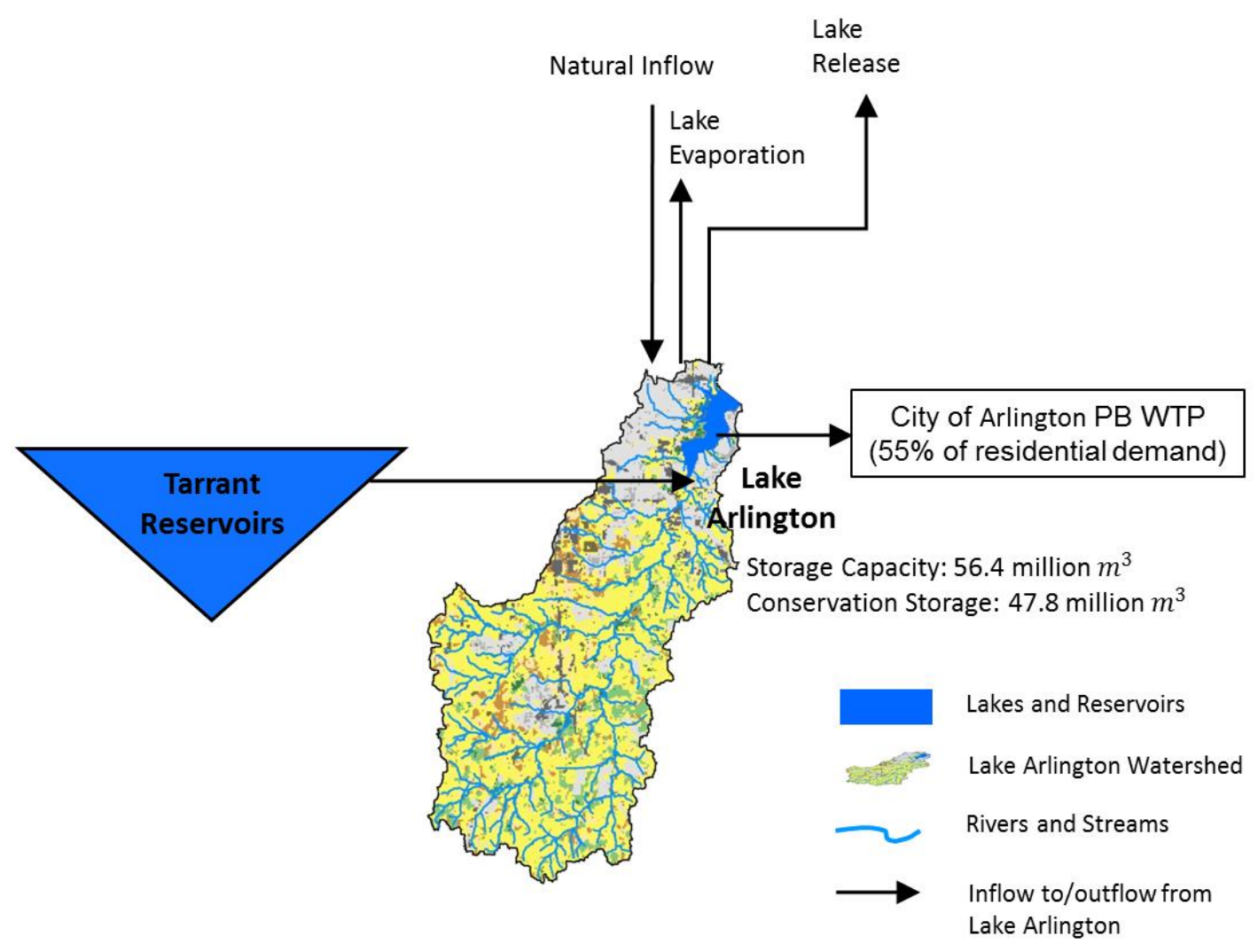

Figure 1. Schematic diagram of Arlington Water System with arrows indicating inflows to and outflows from Lake Arlington.

Table 2. Regression Model Coefficients.

\begin{tabular}{cccc}
\hline Month & Slope $\left(\mathbf{\$} \mathbf{m}^{\mathbf{3}}\right)$ & Y-axis Intercept $(\boldsymbol{\$})$ & $\boldsymbol{R}^{\mathbf{2}}$ \\
\hline January & 0.0613 & $-23,720$ & 0.89 \\
February & 0.0513 & 8113 & 0.79 \\
March & 0.0520 & $-11,031$ & 0.88 \\
April & 0.0504 & $-24,463$ & 0.91 \\
May & 0.0297 & 27,827 & 0.68 \\
June & 0.0459 & 5701 & 0.49 \\
July & 0.0376 & 16,952 & 0.30 \\
August & 0.0276 & 95,504 & 0.31 \\
September & 0.0422 & 5155 & 0.70 \\
October & 0.0540 & $-23,045$ & 0.82 \\
November & 0.0663 & $-56,266$ & 0.86 \\
December & 0.0670 & $-35,984$ & 0.91 \\
\hline
\end{tabular}

\subsection{Instream Flow Calculation}

To calculate the instream flow requirement downstream of Lake Arlington, historical monthly rainfall data from 1999 to 2008 were collected from Texas Water Development Board (TWDB); it is assumed that this period represents an average decade. Runoff time series from the watershed was calculated using Rational Method, and the monthly instream flow requirement was calculated as $10 \%$ of the runoff for the corresponding month. The 10-year average instream flow is estimated as the required instream flow. 


\subsection{Optimization Scenarios}

Two optimization scenarios are developed to explore water management strategies. In Scenario-1, the cost and outdoor watering restriction objectives are included in the model (Equations (6) and (7). In Scenario-2, the cost and environmental reliability objectives are included in the model (Equations (6) and (8)). For both scenarios, constraints are applied to ensure that total demand is met during the simulation period (Equation (9)). The constraint is formulated as a penalty function, which adds a large value to each objective function for a solution that results in shortages. A shortage occurs when demand exceeds the system's capacity. In reality, there has never been a temporary shutdown of the water system due to water shortage during drought; the water district implements stage-3 outdoor watering restriction for prolonged period of time. The instream flow requirement (Equation (10)) is applied for Scenario-2 alone. To ensure that the instream flow requirement is met, for any month in which the reservoir release was zero, the reservoir release is simulated as the volume specified by the instream flow requirement. Inter-basin transfers and water use restrictions are initiated based on water levels falling in Lake Arlington, and the precipitation data is simulated as the rainfall records from 1948 to 1957 , representing a historical drought decade in Texas. For both scenarios, a set of non-dominated optimal management policies are identified, and it is assumed that a non-dominated policy for a drought year would also be suitable for an average year.

\section{Results}

\subsection{Preliminary Results and Algorithm Performance}

A set of preliminary trials was simulated to identify algorithmic parameters settings for NSGA-II. The convergence of the algorithm was measured in terms of hypervolume [41], which measures the extent of the non-dominated solutions in the objective space. The hypervolume value increases when solutions move to more diverse sections of the Pareto front and when the set of non-dominated solutions moves further away from the worst point in solution space. The global worst point for this problem was identified as \$51,388,500 as pumping cost, 3164 days as outdoor watering restrictions, and 0 as environmental reliability. For a set of preliminary trials, parameter settings that performed best based on the maximum value of hypervolume are: mutation rate of 0.01 , crossover rate of 1.0 , population size of 100 , and generations of 100 .

The CAS framework was executed for 10 independent random trials for both Scenario-1 and Scenario-2. Figures 2 and 3 show the convergence of NSGA-II in terms of hypervolume for the best trial for Scenario-1 and Scenario-2, respectively. For each trial, the hypervolume increases over the generations and reaches a plateau before 100 generations. The fluctuations in hypervolume values at the initial generations indicate a loss in fitness quality; this behavior is not surprising because the hypervolume is measured here, not optimized. 


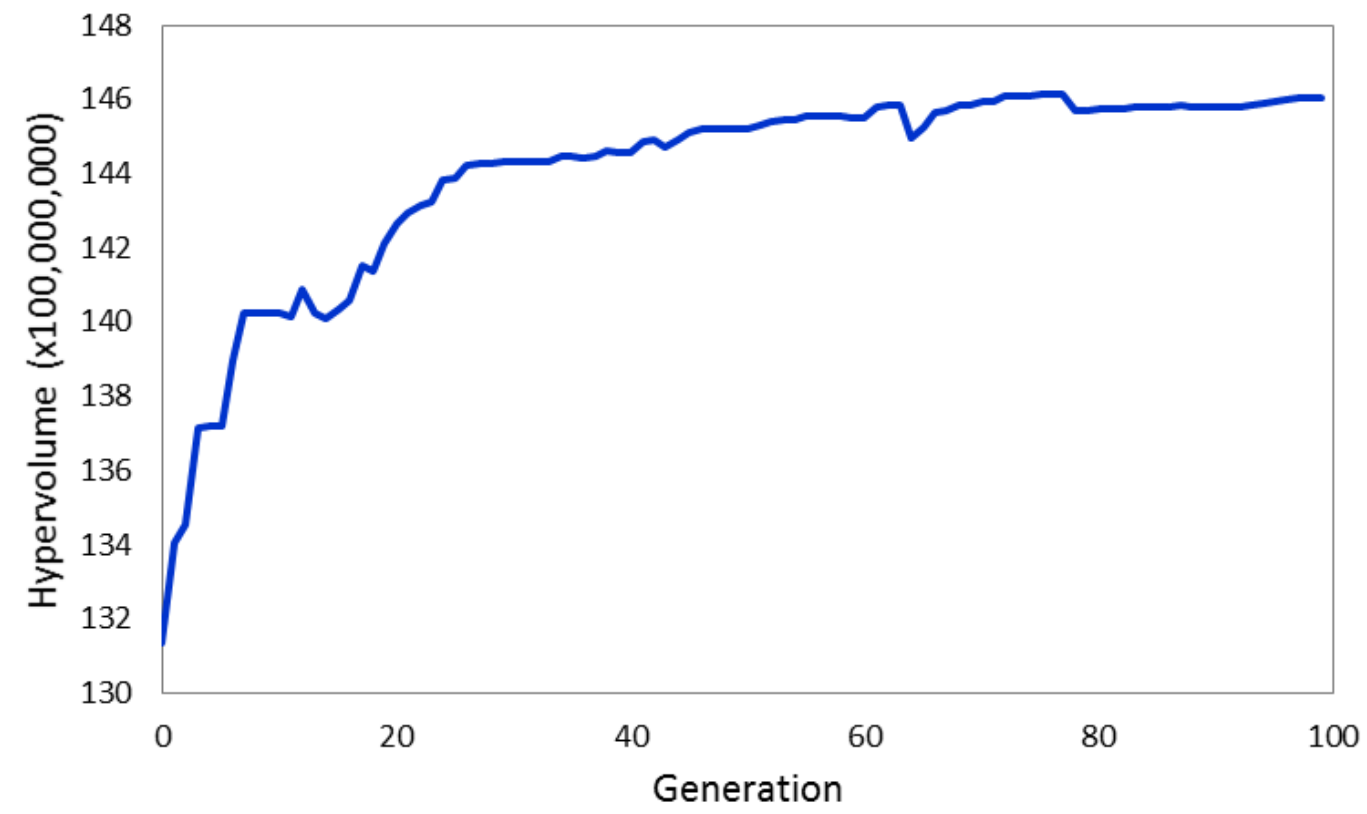

Figure 2. Hypervolume metric for multi-objective water resources system problem for Scenario 1.

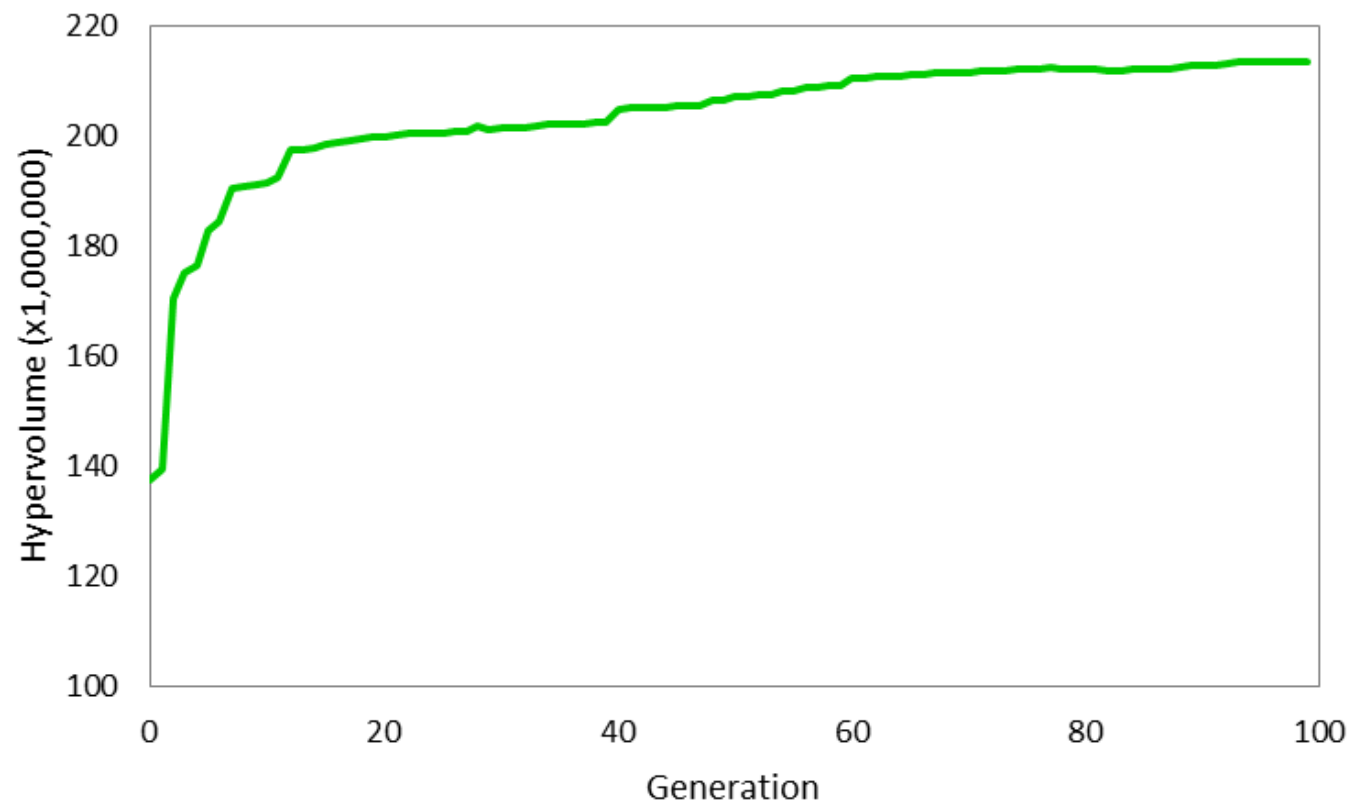

Figure 3. Hypervolume metric for multi-objective water resources system problem for Scenario 2.

\subsection{Scenario-1: Optimizing Cost and Outdoor Watering Restrictions}

The set of solutions from the best of 10 trials for Scenario-1 is shown in Figure 4, in which each point represents a non-dominated solution indicating the cost of inter-basin transfers and number of days when outdoor watering was restricted. In the figure, both the axes represent a minimization objective; thus the Pareto front is oriented from upper left to lower right with sub-optimal regions above and right of the front. In this scenario, the demand was met at all times with no environmental release constraints. 


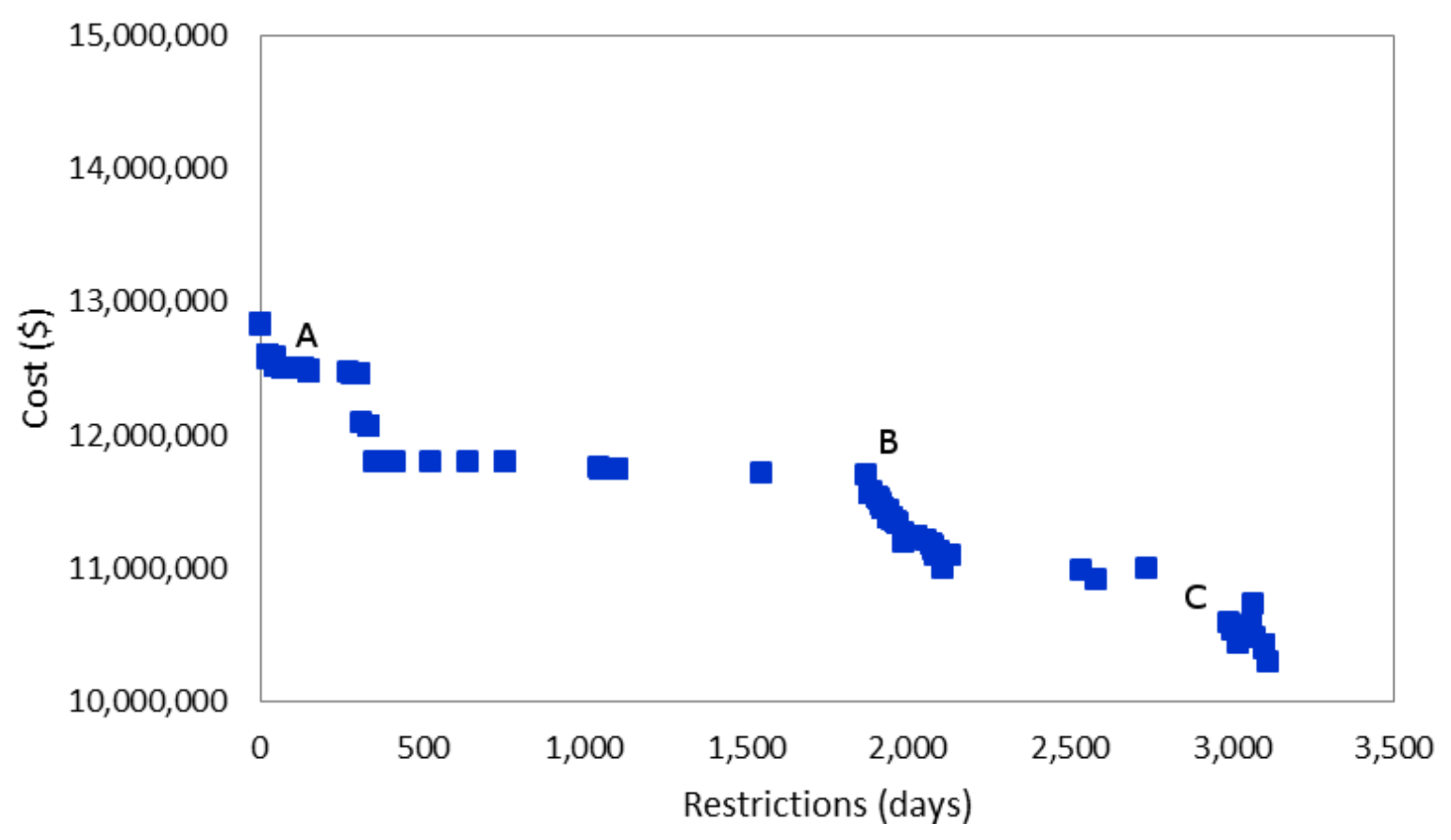

Figure 4. Pareto front for Arlington Water System after 100 generations: Scenario-1.

To examine the tradeoff between the conflicting objectives, three non-dominated solutions (A, B, and C) are selected from the set of non-dominated solutions (Figure 4). These solutions are chosen deliberately based on their diversity on the Pareto front. The objective function values and decision values of the selected solutions are listed in Table 3. Solution-A is a high cost policy with low drought triggers, which results in less frequent implementation of outdoor watering restrictions. Solution-B is a moderate cost policy, which applies a more frequent stages 1 and 2 outdoor watering restrictions, however, the pumping triggers are at and below $11 \%$ of the conservation storage; this results in low volumes of water pumped. Solution-C is a low cost, high restriction policy, which implements stage 2 restrictions 32 times and stage 3 restrictions 74 times during the drought decade. Due to stringent restrictions, as well as moderate pumping throughout the drought decade, this policy maintains a low cost. Figure 5 shows the monthly storage of Lake Arlington resulting from the above three policy decisions (A, B and C) during the simulation period (1948-1957). It is observed that during this historical drought, the system does not run dry. This is due to several reasons: first, the system was optimized assuming the residential demand is met; second, there were no pumping restrictions for inter-basin transfers; and finally, there were no environmental release requirements. As a result, the range of cost values among the non-dominated solutions are relatively similar; however, the solutions provide diversity in outdoor watering restriction options over the simulation period. 
Table 3. Summary of selected solutions on Pareto fronts of Scenario-1 (Solutions A, B, and $\mathrm{C}$ in Figure 4) and Scenario-2 (Solutions D, E, and F in Figure 6).

\begin{tabular}{|c|c|c|c|c|c|c|}
\hline & \multicolumn{3}{|c|}{ Scenario-1 Solutions } & \multicolumn{3}{|c|}{ Scenario-2 Solutions } \\
\hline & $\mathbf{A}$ & B & $\mathrm{C}$ & D & $\mathbf{E}$ & $\mathbf{F}$ \\
\hline \multicolumn{7}{|l|}{ Objectives } \\
\hline $\operatorname{Cost}(\$)$ & $12,512,735$ & $11,713,345$ & $10,546,044$ & $16,895,344$ & $23,053,146$ & $30,321,941$ \\
\hline Restriction (days) & 68 & 1868 & 3000 & - & - & - \\
\hline $\begin{array}{c}\text { Environmental } \\
\text { Reliability }\end{array}$ & - & - & - & 1.01 & 3.50 & 5.56 \\
\hline \multicolumn{7}{|l|}{ Decision Variables } \\
\hline$X(\%)$ & 24 & 11 & 24 & 88 & 97 & 81 \\
\hline$Y(\%)$ & 11 & 6 & 17 & 46 & 79 & 56 \\
\hline$P_{1}(a c-f t)$ & 39 & 150 & 101 & 175 & 996 & 6777 \\
\hline$P_{2}(a c-f t)$ & 429 & 1291 & 966 & 219 & 1500 & 9569 \\
\hline$P_{3}(a c-f t)$ & 7841 & 7981 & 6987 & 9528 & 9801 & 9754 \\
\hline$S_{1}(\%)$ & 18 & 44 & 92 & 91 & 58 & 41 \\
\hline$S_{2}(\%)$ & 13 & 29 & 66 & 75 & 21 & 15 \\
\hline$S_{3}(\%)$ & 9 & 21 & 49 & 67 & 15 & 12 \\
\hline Pumping Volume $(a c-f t)$ & 253,792 & 242,979 & 217,813 & 342,355 & 453,935 & 560,903 \\
\hline \multicolumn{7}{|l|}{ Drought Stages (no.) } \\
\hline Stage-1 & 2 & 39 & 8 & 40 & 0 & 0 \\
\hline Stage-2 & 0 & 29 & 32 & 20 & 0 & 0 \\
\hline Stage-3 & 1 & 14 & 74 & 39 & 0 & 0 \\
\hline
\end{tabular}

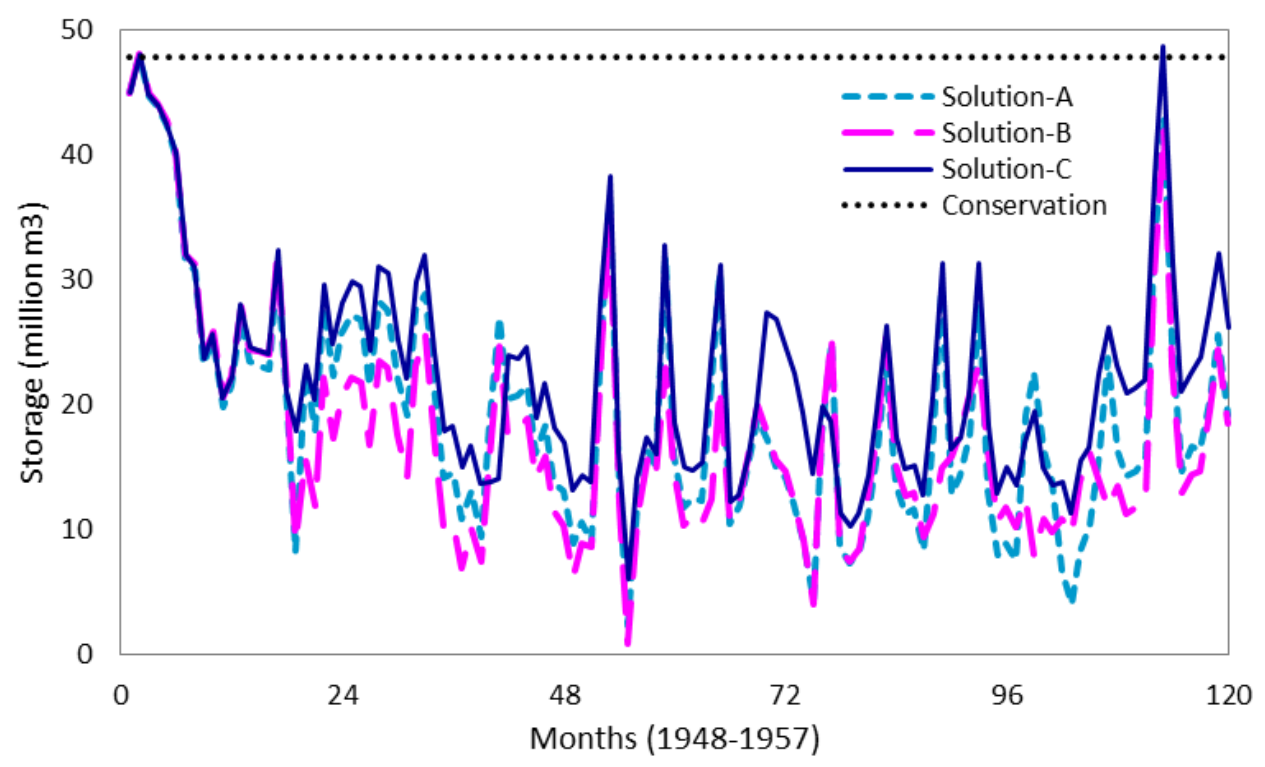

Figure 5. Simulated reservoir storage for Scenario-1 during drought decade.

\subsection{Scenario-2: Minimization of Cost and Maximization of Environmental Reliability}

The non-dominated front of the final solutions from the best of the 10 trials for Scenario- 2 is shown in Figure 6. In this figure, the horizontal axis represents maximization of environmental reliability and the vertical axis represents minimization of cost; the Pareto front is oriented from upper right to lower 
left with sub-optimal regions above and left of the front. In this scenario, the reservoir releases were maintained at or above the instream flow requirements and demands were satisfied (no shortages were allowed in solutions).

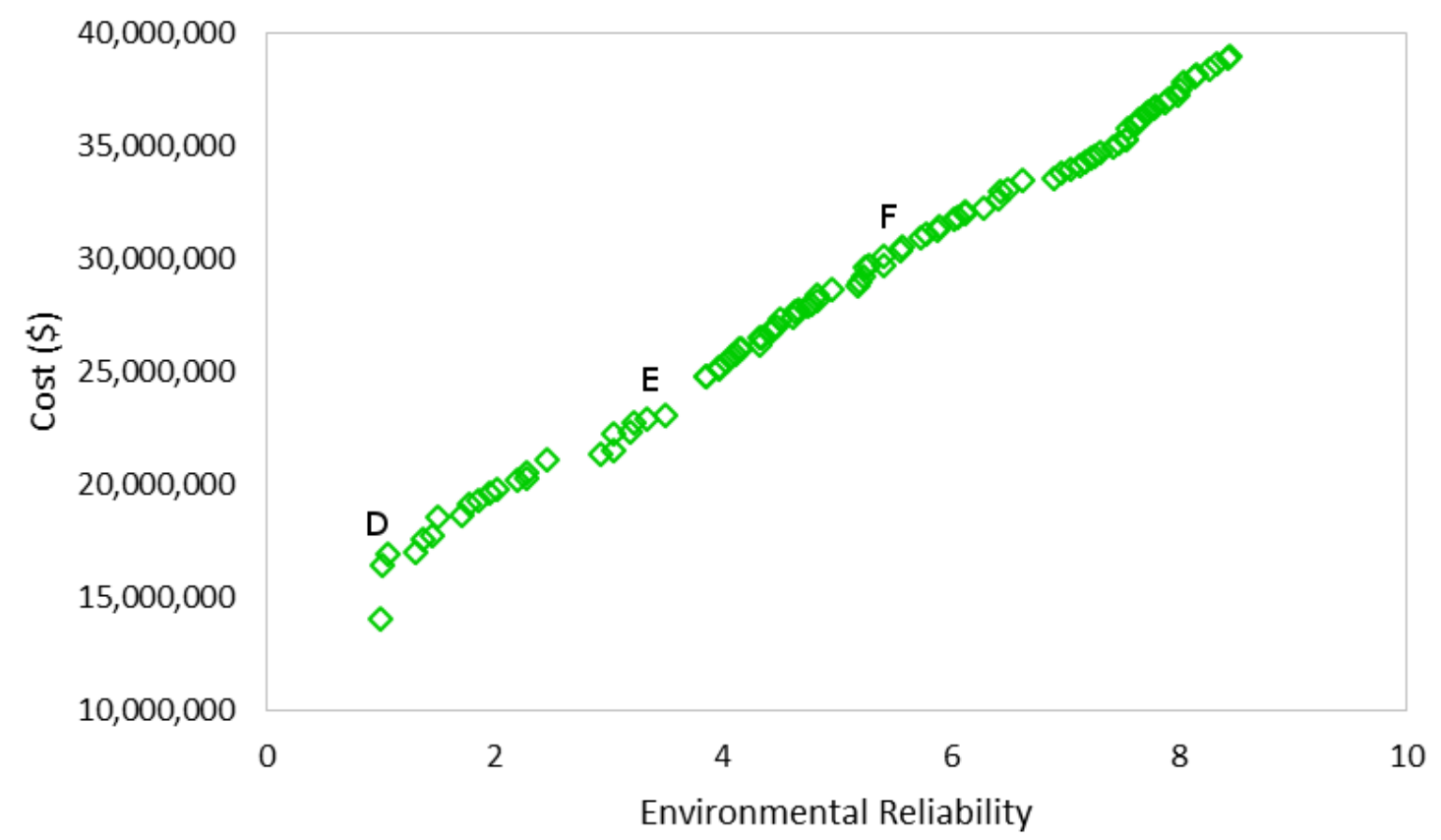

Figure 6. Pareto front for Arlington Water System after 100 generations: Scenario-2.

Three non-dominated solutions (D, E and F) are compared for their conflicting objectives (Figure 6). The corresponding values of the objective functions as well as the decision variables of the above solutions are listed in Table 3. Solution D represents a low cost solution with environmental reliability just above 1.0. There is relatively low pumping during the simulated periods, and this solution results in 2372 days without lawn watering while maintaining both consumer demand and instream flow requirements. Solutions $\mathrm{E}$ and $\mathrm{F}$ are moderate and high cost solutions, respectively, with higher values for environmental reliability. These solutions do not apply any outdoor watering restrictions during the simulation period, but pump large volumes of water. Figure 7 shows that the monthly storage of Lake Arlington for the three solutions ( D, E and F) remains nearly full during the simulation period. With the low cost policy (Solution-D) the reservoir level is close to conservation pool level; with moderate to high cost policies (Solution-E and Solution-F), the reservoir level remains above the conservation pool. In this scenario, the volume of inter-basin transfers is increased in order to meet both civic and environmental requirements. This results in no implementation of restrictions, which, in turn, causes a higher range of costs compared to that of Scenario 1. This may be a good strategy for water districts where protection of endangered marine species is critical. 


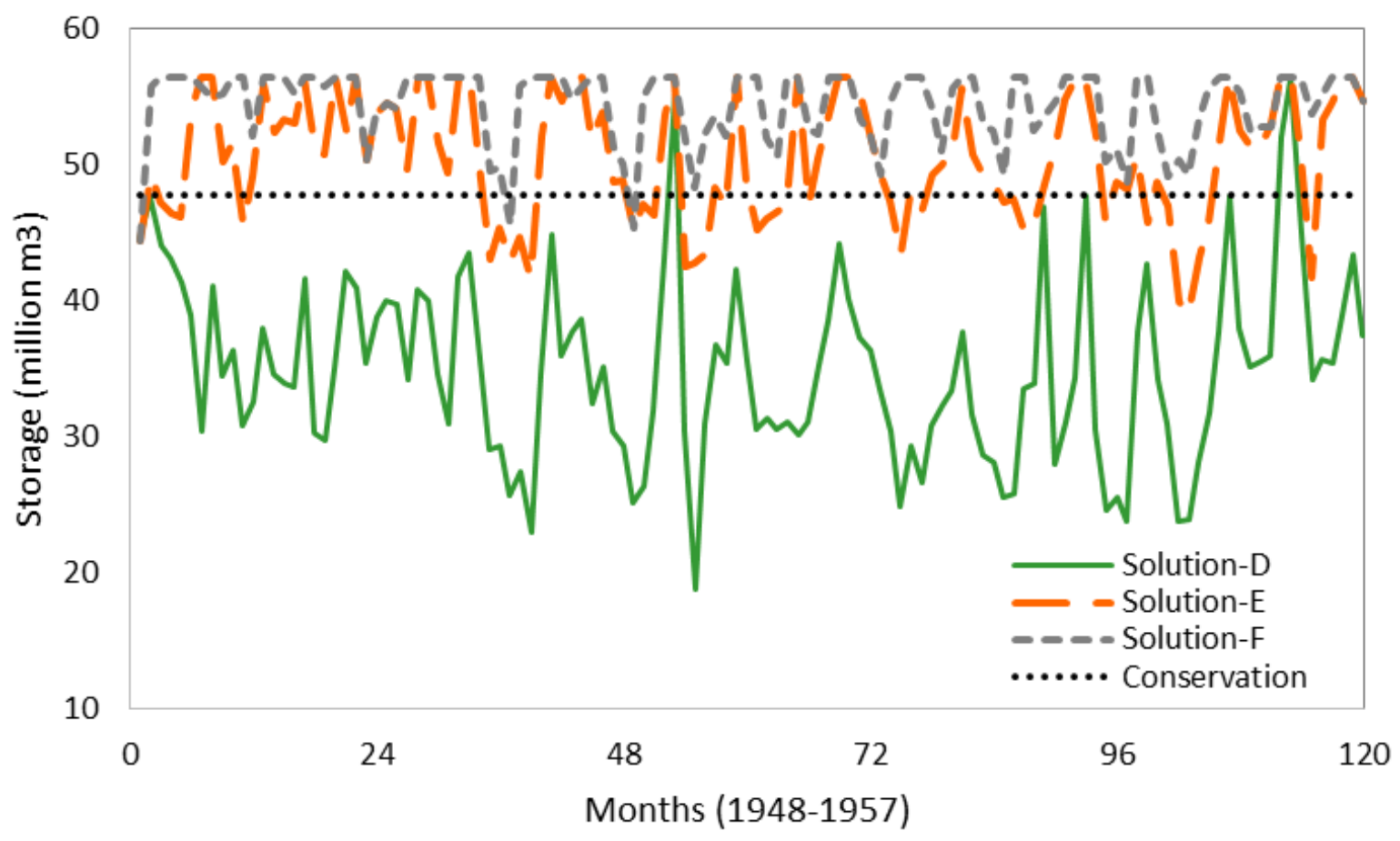

Figure 7. Simulated reservoir storage for Scenario-2 during drought decade.

\section{Discussion}

Two optimization scenarios have been demonstrated here to develop optimal management policies for Arlington Water System. The scenarios are mapped to address sustainable water management in terms of two metrics, in addition to cost: outdoor watering restrictions (in Scenario-1) and environmental reliability (in Scenario-2). Although the model decision variables remain the same for both scenarios, the model generated different non-dominated solutions based on the above metrics. Figures 8 and 9 show the average values of supply side decision variables from the non-dominated solutions on the Pareto fronts for both the scenarios; the error bars represent corresponding standard deviations. Referring to Table 1 and Figure 8, the pumping trigger levels ( $X$ and $Y$ ) are relatively low for Scenario- 1 than that for Scenario-2, with smaller standard deviations for both the scenarios. Lower pumping trigger levels ensure less inter-basin transfer volumes $(P 1$ and $P 2)$ when reservoir water surface elevation is below conservation pool level (CPL) but greater than $X \%$ of CPL and also between $X \%$ and $Y \%$ of CPL (Figure 9). The low values of pumping triggers as well as transfer volumes allow the reservoir levels to drop below the conservation pool (Figure 5). When the reservoir water surface elevation goes below $Y \%$ of CPL, the solutions allow higher volumes of inter-basin transfers (P3) (Figure 9) to meet the consumer demand during historical drought. This is realistic because Scenario-1 satisfies the "no shortage" in demand condition without satisfying the instream flow requirements. Scenario-2, on the other hand, satisfies both the above constraints and hence, the inter-basin transfer volumes ( $P 1, P 2$, and $P 3)$ are much larger than those in Scenario-1 (Figure 9). The high settings for pumping triggers (Figure 8) and high inter-basin transfer volumes (Figure 9) assures that the environmental release constraint is satisfied while meeting the consumer demands. Thus, this scenario also maintains reservoir storage close or above the conservation storage during the simulation period (Figure 7). 


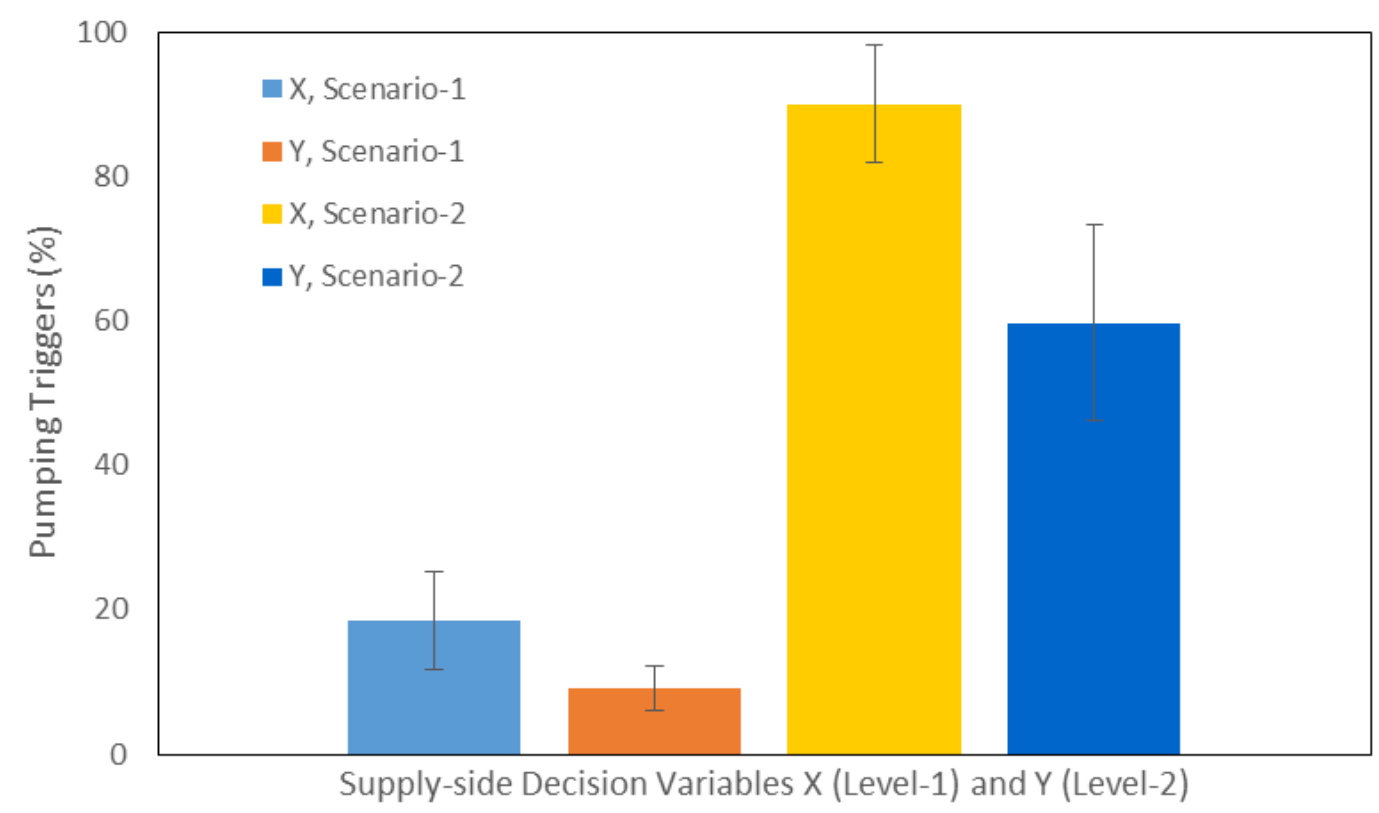

Figure 8. Pareto-optimal pumping trigger levels for Scenario-1 and Scenario-2.

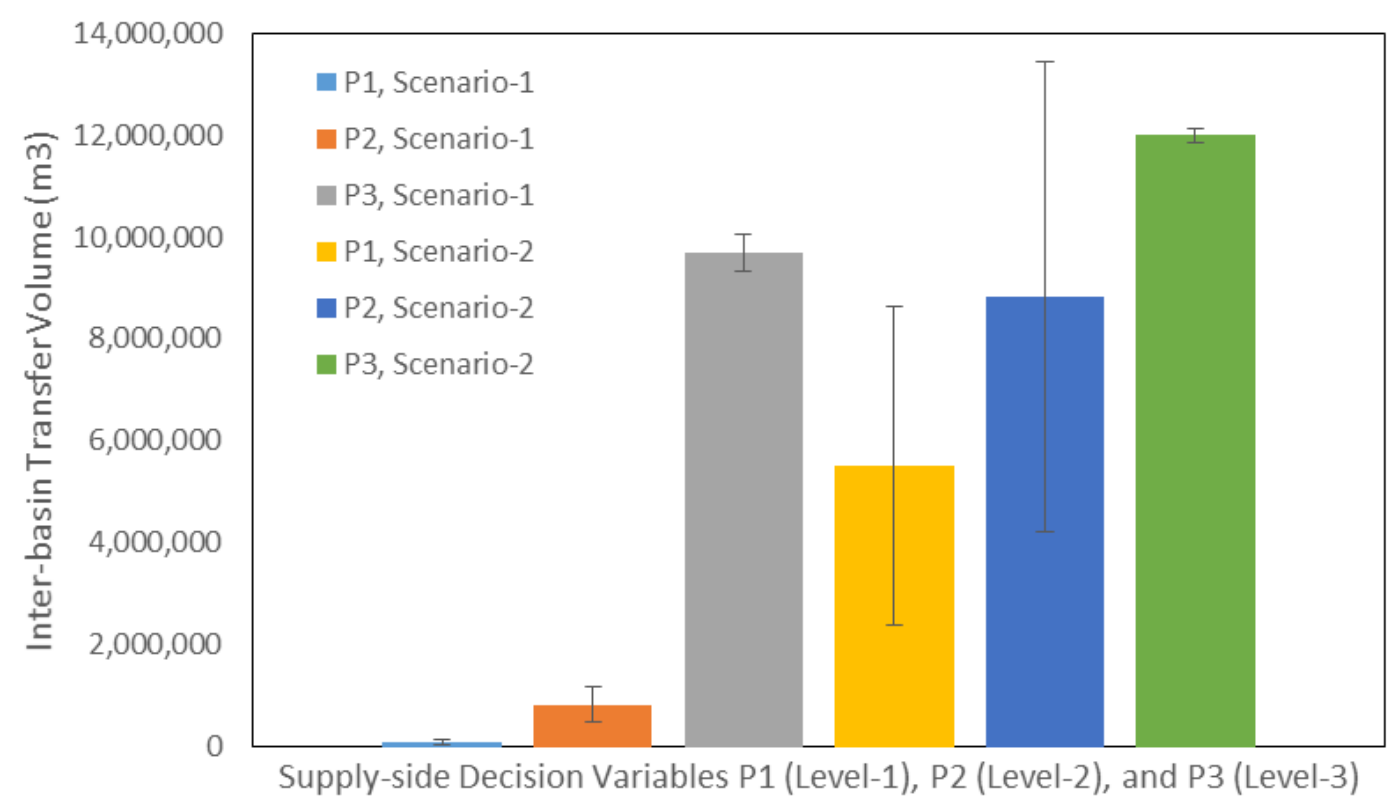

Figure 9. Pareto-optimal inter-basin transfer volumes for Scenario-1 and Scenario-2.

The average values of demand-side decision variables with corresponding standard deviations are shown in Figure 10 for both Scenario-1 and Scenario-2. The lower average values of drought stage triggers $(S 1, S 2$, and $S 3)$ for Scenario-1 along with the nearness in their respective values represent that when the demand is stressed, this scenario implements drought stage triggers frequently to avoid possible drought. The larger values in standard deviation of drought stage triggers along with higher volumes of level 3 inter-basin transfers (P3) help bring the system into balance. For Scenario-2, the non-dominated drought stage triggers $(S 1, S 2$, and $S 3$ ) show higher values than that of Scenario-1 but higher standard deviation values similar to Scenario-1 results (Figure 10). Compared to the pumping trigger values (X and $\mathrm{Y}$ in Figure 8), this scenario implements smaller values of drought triggers (S1,S2, and $S 3)$, which results in low or no days without lawn watering. 


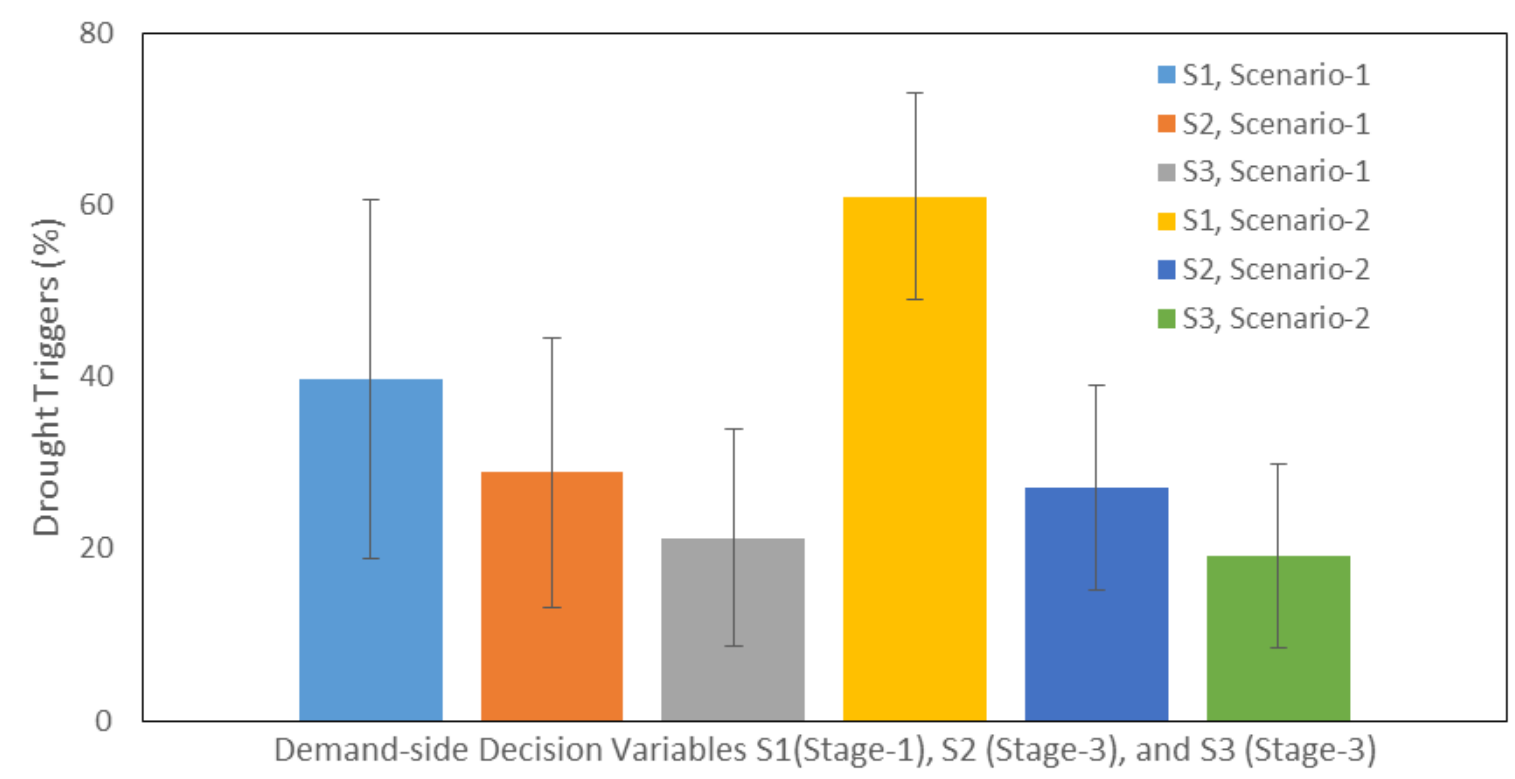

Figure 10. Pareto-optimal drought stage trigger levels for Scenario-1 and Scenario-2.

\section{Conclusions}

In this study, a simulation-optimization methodology is developed by coupling a CAS modeling framework with NSGA-II optimization methodology, and the model is demonstrated to identify optimal supply-side and demand-side management strategies for an urban water resources system. The major contribution of this research is modeling feedback loops among consumers, policy makers, and natural water resources while evaluating optimal management policies based on the tradeoffs between supply-side and demand-side options. Arlington Water System is used as a case study to investigate non-dominated policies of inter-basin transfers and outdoor watering restrictions.

Urban water resources systems are typically planned and operated to meet consumer demands even during severe droughts. Due to population growth, urbanization, and climate change, water may become scarce, and water resources require careful planning to sustainably meet demands while reducing water stress on environmental and ecological systems. Although demand is greatly influenced by climate change, conservation policies, and consumer behaviors, existing water management methods ignore the interactions between consumers and policy makers in developing optimal management strategies. This study explicitly addresses the interaction between consumers and policy makers in managing a water resources system. The simulation-optimization model incorporates population growth, word of mouth communication, and several conservation-based policies, including retrofitting plumbing fixtures while optimizing the system for minimum cost and maximum drought security.

In this study, two scenarios are developed to generate non-dominated solutions. The first scenario explores tradeoffs between outdoor watering restrictions and cost of inter-basin water transfers; the second scenario explores tradeoffs in environmental reliability and pumping costs. In both the scenarios, the model ensures that there are no water shortages experienced by residential consumers. When outdoor watering restrictions are minimized in Scenario-1, the solutions are identified that are characterized by low pumping triggers and high drought triggers, resulting in more frequent implementation of outdoor watering restrictions and less frequent inter-basin transfers. Thus the reservoir storage stayed below the conservation storage level, without running completely dry, during the simulation period. In Scenario-2, 
environmental reliability is maximized with an additional constraint of instream flow requirements downstream of the reservoir. Due to this constraint, the model generates solutions with high pumping triggers as well as high drought triggers, which result in frequent inter-basin transfers and outdoor watering restrictions. In this case, the reservoir storage for most solutions remained close to the conservation storage.

While minimizing the cost of inter-basin transfers, the Pareto-optimal solutions from Scenario-1 show a narrow range in cost. This is mainly because of three reasons: (1) Lake Arlington has a limited storage capacity; (2) inter-basin transfer strategies are influenced by climate and demand; and (3) there is no minimum release or instream flow requirements. For Scenario-2, due to both instream flow requirements and no restrictions in pumping, the non-dominated solutions show a wide range in cost. A study of a third scenario with minimization of cost, minimization of outdoor watering restrictions, and maximization of instream flow requirements could be done for regions where instream flows are vital for the ecosystem. Currently, the coupled CAS and NSGA-II framework requires $64.5 \mathrm{~h}$ to execute one trial (100 generations) in a Core 2 Quad CPU with a $2.83 \mathrm{GHz}$ processor and 8.00 GB RAM.

A few operations of the real system could not be represented through the ABM. Although the model was able to demonstrate successful demand management through outdoor conservation, the model assumes all outdoor watering restrictions are mandatory; hence all agents comply, resulting in frequent implementation of restrictions during Scenario-1. Moreover, the model parameter values representing households behavioral choice of watering the lawns $(f=2.0,1.0,0.5$, and 0.0$)$ were based on a study in South Africa [34], not based on the study area. Calibration of the ABM is outside the scope of this work and will be addressed in future studies.

In conclusion, this case study demonstrated the ability of a coupled CAS and NSGA-II simulation-optimization framework to generate management solutions for a complex system subjected to changing demographic and climatic conditions. In future research, simulation frameworks can build on land use change simulation [9] to explore Pareto-optimal water-use and land-use strategies for sustainable management of urban water resources.

\section{Acknowledgments}

The authors express their appreciation to the City of Arlington and Tarrant Regional Water District for their support and sharing of valuable data, reports, and insights. Any opinions, findings, and conclusions or recommendations expressed in this paper are those of the authors and do not necessarily reflect the views of either City of Arlington or Tarrant Regional Water District. The authors express gratitude to the editorial board and two anonymous reviewers for their detailed attention to the paper and their many helpful comments and suggestions to improve the manuscript. This material is based on work supported by the National Science Foundation under Grant ECC-0926893.

\section{Author Contributions}

L.K. contributed to model development, model implementation, generation of results, analysis, and reporting. E.Z.B. contributed to model development, analysis, and reporting. 


\section{Conflicts of Interest}

The authors declare no conflict of interest.

\section{References}

1. Marvin, S.; Graham, S.; Guy, S. Cities, regions and privatised utilities. Prog. Plan. 1999, 51, 91-165.

2. Galán, J.M.; López-Paredes, A.; del Olmo, R. An agent-based model for domestic water management in Valladolid metropolitan area. Water Resour. Res. 2009, 45, 1-17.

3. Stiles, G. Demand-side management, conservation, and efficiency in the use of Africa's water resources. In Water Management in Africa and the Middle East: Challenges and Opportunities; International Development Research Center: Ottawa, ON, Canada, 1996; pp. 3-38.

4. Michelsen, A.; McGuckin, J.T.; Stumpf, D. Nonprice water conservation program as a demand management tool. J. Am. Water Resour. Assoc. 1999, 35, 593-602.

5. Field, C.B.; Barros, V.R.; Dokken, D.J.; Mach, K.J.; Mastrandrea, M.D.; Bilir, T.E.; Chatterjee, M.; Ebi, K.L.; Estrada, Y.O.; Genova, R.C.; et al. Climate Change 2014 Impacts, Adaptation, and Vulnerability Part A: Global and Sectoral Aspects; Cambridge University Press: New York, NY, USA, 2014.

6. Neal, M.J.; Lukasiewicz, A.; Syme, G.J. Why justice matters in water governance: Some ideas for a "water justice framework." Water Policy 2014, 16, 1-18.

7. MacDonald, D.H.; Crossman, N.D.; Mahmoudi, P.; Taylor, L.O.; Summers, D.M.; Boxall, P.C. The value of public and private green spaces under water restrictions. Landsc. Urban Plan. 2010, 95, 192-200.

8. Zeff, H.B.; Kasprzyk, J.R.; Herman, J.D.; Reed, P.M.; Characklis, G.W. Navigating financial and supply reliability tradeoffs in regional drought management portfolios. Water Resour. Res. 2014, 50, 4906-4923.

9. Giacomoni, M.H.; Kanta, L.; Zechman, E. Complex Adaptive Systems Approach to Simulate the Sustainability of Water Resources and Urbanization. J. Water Resour. Plan. Manag. 2013, 139, 554-564.

10. Kanta, L.; Zechman, E. Complex adaptive systems framework to assess supply-side and demand-side management for urban water resources. J. Water Resour. Plan. Manag. 2014, 140, $75-85$.

11. Deb, K.; Agarwal, S.; Meyarivan, T. A fast and elitist multiobjective genetic algorithm: NSGA-II. IEEE Trans. Evolut. Comput. 2002, 6, 182-197.

12. Randall, D.; Houck, M.H.; Wright, J.R. Drought Management of Existing Water Supply System. J. Water Resour. Plan. Manag. 1990, 116, 1-20.

13. Cui, L.; Kuczera, G. Optimizing water supply headworks operating rules under stochastic inputs: Assessment of genetic algorithm performance. Water Resour. Res. 2005, 41, 1-9.

14. Kim, T.; Heo, J.-H.; Jeong, C.-S. Multireservoir system optimization in the Han River basin using multi-objective genetic algorithms. Hydrol. Process. 2006, 20, 2057-2075. 
15. Yang, C.-C.; Chang, L.-C.; Yeh, C.-H.; Chen, C.-S. Multiobjective planning of surface water resources by multiobjective genetic algorithm with constrained differential dynamic programming. J. Water Resour. Plan. Manag. 2007, 133, 499-508.

16. Kim, T.; Heo, J.-H.; Bae, D.-H.; Kim, J.-H. Single-reservoir operating rules for a year using multiobjective genetic algorithm. J. Hydroinformat. 2008, 10, 163-179.

17. Kasprzyk, J.R.; Reed, P.M.; Kirsch, B.R.; Characklis, G.W. Managing population and drought risks using many-objective water portfolio planning under uncertainty. Water Resour. Res. 2009, 45, 1-18.

18. Lund, J.R. Evaluation and Scheduling of Water Conservation. J. Water Resour. Plan. Manag. 1987, 113, 696-708.

19. Wilchfort, O.; Lund, J.R. Shortage management modeling for urban water supply systems. J. Water Resour. Plan. Manag. 1997, 123, 250-258.

20. Jenkins, M.W.; Lund, J.R. Integrating Yield and Shortage Management under multiple uncertainties. J. Water Resour. Plan. Manag. 2000, 126, 288-297.

21. Reddy, M.J.; Kumar, N. Optimal reservoir operation using multi-objective evolutionary algorithm. Water Resour. Manag. 2006, 20, 861-878.

22. Mortazavi, M.; Kuczera, G.; Cui, L. Multiobjective optimization of urban water resources: Moving toward more practical solutions. Water Resour. Res. 2012, 48, 1-15.

23. House-Peters, L.A.; Chang, H. Urban water demand modeling: Review of concepts, methods, and organizing principles. Water Resour. Res. 2011, 47, 1-15.

24. Miller, J.H.; Page, S.E. Complex Adaptive Systems: An Introduction to Computational Models of Social Life; Princeton University Press: Princeton, NJ, USA, 2007.

25. Pahl-wostl, C. Transitions towards adaptive management of water facing climate and global change. Water Resour. Manag. 2007, 21, 49-62.

26. Yang, A.; Shan, Y. Intelligent Complex Adaptive Systems; IGI Publishing: Hershey, NY, USA, 2008.

27. Moss, S.; Downing, T.; Rouchier, J. Demonstrating the Role of Stakeholder Participation: An Agent Based Social Simulation Model of Water Demand Policy and Response; Manchester Metropolitan University: Manchester, UK, 2000.

28. Athanasiadis, I.N.; Mentes, A.K.; Mitkas, P.A.; Mylopoulos, Y.A. A Hybrid Agent-Based Model for Estimating Residential Water Demand. Simulation 2005, 81, 175-187.

29. Rixon, A.; Moglia, M.; Burn, S. Exploring Water Conservation Behavior through Participatory Agent-Based Modeling. In Topics on System Analysis and Integrated Water Resources Management; Elsevier: Oxford, UK, 2007.

30. Perugini, D.; Perugini, M.; Young, M. Water Saving Incentives: An Agent-Based Simulation Approach to Urban Water Trading. In Simulation Conference: Simulation-Maximising Organisational Benefits. Intelligent Software Development: Melbourne, Australia, 2008.

31. Chu, J.; Wang, C.; Chen, J.; Wang, H. Agent-based residential water use behavior simulation and policy implications: A case-study in Beijing city. Water Resour. Manag. 2009, 23, 3267-3295.

32. Giacomoni, M.H.; Berglund, E.Z. A Complex Adaptive Simulation Framework for Evaluating Adaptive Demand Management for Urban Water Resources Sustainability. J. Water Resour. Plan. Manag. 2015, 141, 1-12.

33. XJ Technology. AnyLogic 6.5 (Version 6.5). Available online: http://www.xjtek.com (accessed on 23 March 2010). 
34. Jacobs, H.E.; Haarhoff, J. Structure and data requirements of an end-use model for residential water demand and return flow. Water SA 2004, 30, 293-304.

35. Watts, D.J.; Strogatz, S.H. Collective dynamics of "small-world" networks. Nature 1998, 393, 440-442.

36. Kuichling, E. The relation between the rainfall and the discharge of sewers in populous districts. Trans. Am. Soc. Civil Eng. 1889, 1, 1-56.

37. Cai, X.; Rosegrant, M.W. Global water demand and supply projections: Part 1, a modeling approach. Water Int. 2002, 27, 159-169.

38. Goldberg, D.E. Genetic Algorithms in Search Optimization, and Machine Learning; Addison-Wesley: New York, NY, USA, 1989.

39. Arlington Water Utilities. Water Conservation Plan. City of Arlington: Arlington, TX, USA, 2014. Available online: http://www.arlington-tx.gov/water/wp-content/uploads/sites/3/2014/07/ City-of-Arlington-Water-Conservation-Plan-2014.pdf (accessed on 28 July 2015).

40. Freese and Nichols Inc., Alan Plummer Associates, CP\&Y Inc., \& Cooksey Communications. 2011 Region C Water Plan. Freese and Nichols, Inc.: Austin, TX, USA, 2010. Available online: http://www.regioncwater.org/Documents/index.cfm?Category=2011+Region+C+Water+Plan (accessed on 28 July 2015).

41. Fleischer, M. The Measure of Pareto Optima Applications to Multi-objective Metaheuristics. In Second International Conference of Evolutionary Multi-Criterion Optimization; Springer: Heidelberg, Germany, 2003; Volume 2632, pp. 519-533.

(C) 2015 by the authors; licensee MDPI, Basel, Switzerland. This article is an open access article distributed under the terms and conditions of the Creative Commons Attribution license (http://creativecommons.org/licenses/by/4.0/). 